\title{
A Contribution to the Thermal Field Evaluation at the Tool-Part Interface for the Optimization of Machining Conditions
}

\author{
Nasreddine Benhadji Serradj \\ Department of Mechanical Engineering \\ University of Tlemcen \\ Tlemcen, Algeria \\ kawther4499@yahoo.fr
}

\author{
Abdelillah Djamal Kara Ali \\ Department of Mechanical Engineering \\ University of Tlemcen \\ Tlemcen, Algeria \\ dj_kara_ali@yahoo.fr
}

\author{
Mohamed El Amine Ghernaout \\ Department of Mechanical Engineering \\ University of Tlemcen \\ Tlemcen, Algeria \\ e_amine2001@yahoo.fr
}

\begin{abstract}
In this study, an experimental measurement methodology is implemented that allows obtaining consistent temperature data during the turning operation of semi-hard C20 steel using SNMG carbide insert, allowing us to have better control at the tool-part interface. The interactions of the phenomena influencing the cut led our choices on the development of a correlation model for the analysis and prediction of the relationships between the machining parameters by measurement of the temperature. The measurement procedure implemented for the temperature estimate is based on the use of an FLIR A325sc type infrared camera mounted and protected by a device on the machine tool. The Taguchi method was chosen to find the relationships between the input factors (cutting speed ( $\mathrm{Vc}$ ), feed rate (a), depth of cut (p)), and the output factor (temperature (T)). In the future, we will develop a numerical validation model to simulate the machining process in order to predict temperatures.
\end{abstract}

Keywords-machining conditions; temperature measurement; infrared camera; thermal transfer; Taguchi plan; emissivity

\section{INTRODUCTION}

During machining, maximum heat occurs at the tool-part interface. It affects, among others, tool life, surface finish, and cutting forces. At the heart of the process, two main phenomena interact: a very strong plastic deformation in the shear zones and the friction of the chip on the cutting face of the tool. We can also add the friction of the draft face on the newly generated surface (Figure 1). Since the first experimental work of Taylor (1905-1907) on the influence of temperature in machining, significant progress has been made in improving knowledge about metal cutting. The bibliographic research carried out in [1] on the different thermal aspects during machining shows the difficulties of direct measurement.
Authors in [2] showed that several methods are possible for measuring temperatures during the cutting process:

- Measurement by metallurgical analysis of the cutting insert after machining. Authors in [3] showed that it is possible to determine the temperature map in the cutting tool as a function of the phase transformations detected during a metallographic analysis of a high speed steel tool. This is an a posteriori measurement method.

- Measurement by thermocouples implanted in the cutting insert. In [4], it was shown that for this type of thermal measurement, the temperature mapping is carried out from point readings obtained by thermocouples implanted in the insert of the cutting tool.

- Temperature evaluation by thermocouples directly in contact with the tool-part pair. In this particular case, only an average value of the temperature can be obtained. Authors in [5] proposed the use of the tool-part contact as a hot junction for the thermocouple. The two preceding methods present major hazards relating to the installation of thermocouples.

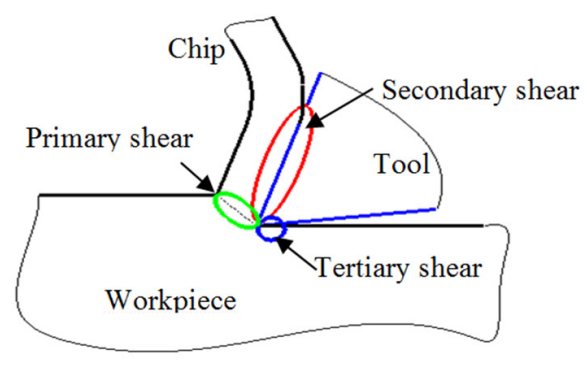

Fig. 1. Sources of heat generation in machining. 
Our job focused on taking the temperature with an infrared camera without contact. The response time is fast, thus allowing the capture of the intermittent heat generation. This capture can allow us to regulate the cutting parameters if there is a sudden increase in temperature. The camera is mounted and protected by a device on the machine tool.

\section{THERMAL FLOWS}

Almost all of the chip formation work is degraded in the form of heat. This results in a high temperature rise in the chip formation zone. The correlation between cutting conditions and temperature is shown in Figure 2, with regard particular to the primary influence of the cutting speed factor.

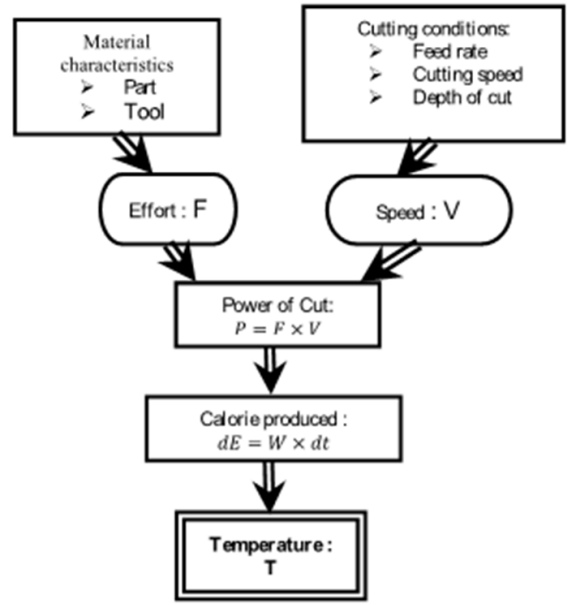

Fig. 2. Correlation between cutting conditions and temperature

In this section, we will recall the modes of heat transfer and the influence factors expressed in this method of measurement. Surface temperature measurements implement three heat transfer modes that we briefly recall below along with the relationships of the listed laws.

- Conduction: corresponds to the transfer of heat within an opaque medium, without displacement of matter, under the influence of a temperature difference. Fourier's law (1) describes this transfer mechanism [9-10]:

$$
\phi=\lambda . S \cdot \frac{T_{1}-T_{2}}{\Delta x}
$$

- Convection: corresponds to the transfer of heat between a solid and a moving fluid (liquid or gas). Newton's law (2) describes this transfer mechanism [9-10]:

$$
\phi=h \cdot S\left(\mathrm{~T}_{\mathrm{p}}-\mathrm{T}_{\mathrm{a}}\right)
$$

- Radiation: corresponds to the transfer of heat in the form of an electromagnetic wave, emitted by a surface. Stefan's law (3) describes this transfer mechanism [9-10]:

$$
\phi=\sigma . S . \varepsilon_{\mathrm{p}} \cdot\left(\mathrm{T}_{\mathrm{p}}^{4}-\mathrm{T}_{\mathrm{a}}^{4}\right)
$$

To obtain consistent temperature data at the tool-part interface, an experimental measurement methodology is proposed using acquisition instrumentation, equipped with an infrared camera and a unit for processing the measured values.

\section{MEASUREMENT BY INFRARED RADIATION}

The large amount of heat released in the chip formation zone and the difficulties of evacuation of this generated energy, result in very high and localized temperatures. These in turn have a significant impact on the dimensional and geometric precision of the produced surfaces and the lifetime of the cutting tools. The knowledge of the thermal field is therefore an essential element in the analysis and control of these phenomena.

\section{A. Infrared Thermography}

Thermal imaging is a contactless technology that converts infrared waves into a temperature image. Figure 3 shows schematically the overall principle of this method.

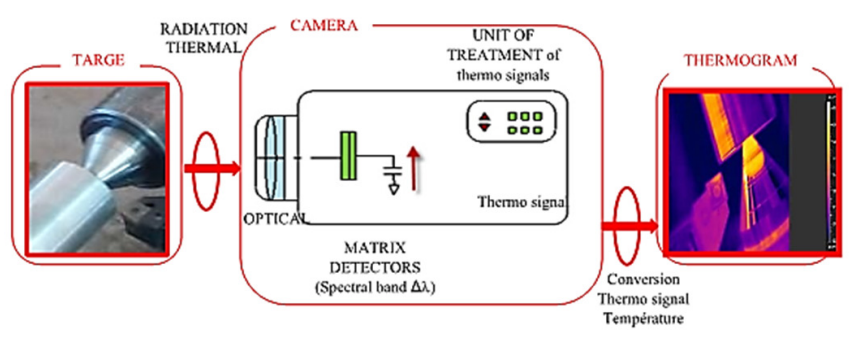

Fig. 3. Radiometric chain of the camera

\section{B. Theoretical Elements}

Increase in temperature due to machining causes electromagnetic radiation described by Planck's law. This law, for a black body, is the basis of temperature measurement by radiation analysis. It has a spectral distribution, which depends on the material. Its intensity or its luminance can be measured and its analysis allows finding the temperature [6].

$$
\mathrm{L}_{\lambda}=\frac{\mathrm{C}_{1}}{\frac{\mathrm{C}_{2}}{\lambda^{5}\left(\mathrm{e}^{\lambda \mathrm{T}_{1}}-1\right)}}
$$

where $\mathrm{C}_{1}$ and $\mathrm{C}_{2}$ are constants: $\mathrm{C}_{1}=1.191 \times 10^{-16} \mathrm{~W} \cdot \mathrm{m}^{2} \cdot \mathrm{sr}^{-1}$ and $\mathrm{C}_{2}=1.438 \times 10^{-2} \mathrm{~m} . \mathrm{K}, \mathrm{h}$ is the Planck constant, $\mathrm{k}$ the Boltzmann constant, $\mathrm{c}$ the speed of light, $\mathrm{T}$ the absolute temperature in Kelvin degrees, and $\lambda$ the wavelength in $\mathrm{m}$ [9-10].

Emissivity $\varepsilon$ is a property of surfaces depending on the nature of the material, its surface quality, the wavelength and the angle of observation. Its prior evaluation is essential to determine the absolute value of the temperature from the light flux signal [7].

$$
\varepsilon=\frac{\mathrm{L}_{\alpha}}{\mathrm{L}_{\beta}}
$$

where $\mathrm{L}_{\alpha}$ is the luminance of the measured object and $\mathrm{L}_{\beta}$ the luminance of the black body [9-10].

\section{EXPERIMENTAL PROCEDURE}

Although the undertaken studies so far in the area of cutting (mechanism of chip formation, behavior of tools, thermal appearance, and damage of the cutting edges) have made significant progress in the understanding of the process, it is necessary to update and continue them, in order to meet the 
new conditions of the industrial context. The complexity and interactions of the many factors involved in the cutting phenomena require specific experiments for each material, in order to define the best choice of tools and corresponding optimal cutting conditions, based on the analysis of their wear behaviors.

\section{A. Means of Realization}

In order to take into account the dominant elements of machining, the current analysis was restricted to steel and conventional machining processes.

- Machine tool used: The machining was carried out on a conventional parallel lathe made by TOS TRENCIN (Figure 4). It is a rigid, powerful, precise and well-sealed machine. The main motor of the machine is asynchronous type.

- Machined material: The material used for these tests is the C20 non-alloy steel for heat treatments frequently used in industry. The chemical composition and physic properties are presented in Tables I and II.

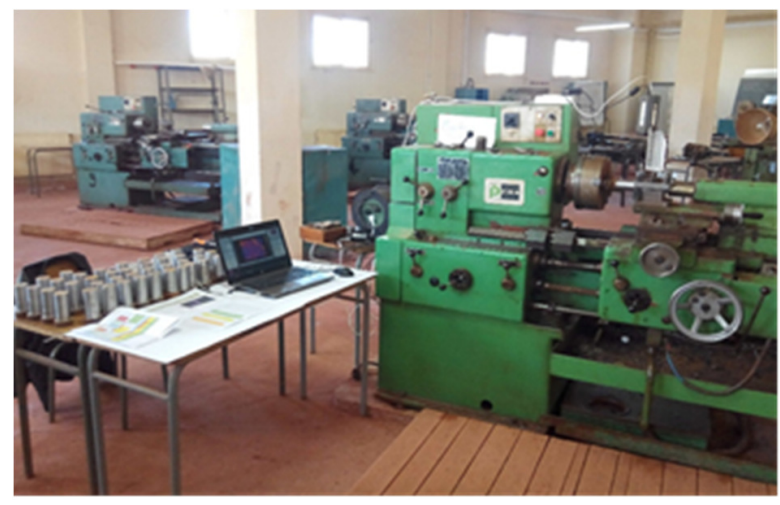

Fig. 4. Radiometric chain of the camera.

TABLE I. CHEMICAL COMPOSITION

\begin{tabular}{|c|c|c|c|c|c|}
\hline Element & $\mathrm{C}$ & $\mathrm{Fe}$ & $\mathrm{Mn}$ & $\mathrm{P}$ & $\mathrm{S}$ \\
\hline $\mathbf{\%}$ & 0.138 & 98.11 & 1.062 & 0.013 & 0.011 \\
\hline
\end{tabular}

TABLE II. PHYSICAL PROPERTIES

\begin{tabular}{|c|c|c|}
\hline Property & Value & Units \\
\hline Elastic modulus & $2.049999984 \mathrm{e}+011$ & $\mathrm{~N} / \mathrm{m}^{2}$ \\
\hline Mass density & 7850 & $\mathrm{Kg} / \mathrm{m}^{3}$ \\
\hline Thermal conductivity & 52 & $\mathrm{~W} /\left(\mathrm{m}^{*} \mathrm{~K}\right)$ \\
\hline Specific heat & 486 & $\mathrm{~J} /\left(\mathrm{kg}^{*} \mathrm{~K}\right)$ \\
\hline
\end{tabular}

- Insert and tool holders: The insert used in our tests were chosen according to the machining conditions and a small beak radius $(\mathrm{r}=0,8 \mathrm{~mm})$. The reference selected is SNMG 12-04-08 (Figure 5). The choice of the tool holder was oriented on a PCLN R 20-20 K12. The properties of the insert are shown in Table III.

- Measurement process used: The objective of this contribution is to measure temperatures in the chip formation zone in order to collect thermal data from the cutting mechanism. The quality of the information sought requires that it be captured as close as possible to the chip creation area. Temperatures were recorded using the FLIR A325sc thermal camera (Figure 6). The camera is coupled with FLIR Research IR Max measuring software for maximum intuitiveness in display, recording and advanced thermal data processing (Figure 7) [8].

TABLE III. INSERT PROPERTIES

\begin{tabular}{|c|c|}
\hline Wafer shape & SNMG \\
\hline Insert size & 120408 \\
\hline Matter & Carbide \\
\hline Insert thickness $(\mathrm{mm})$ & 4.76 \\
\hline Edge length $(\mathrm{mm})$ & 12 \\
\hline Insert radius $(\mathrm{mm})$ & 0.8 \\
\hline Draft angle $\left(^{\circ}\right)$ & 0 \\
\hline Number of cutting edges & 8 \\
\hline
\end{tabular}

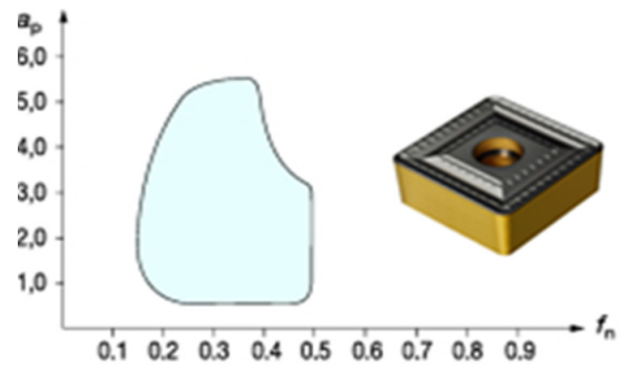

Fig. 5. Pad and its diagram of the range of applications.

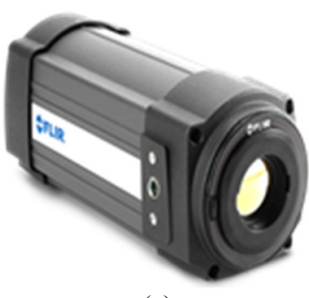

(a)

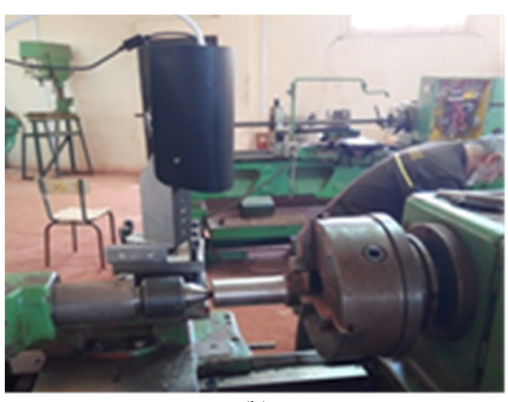

(b)
Fig. 6. (a) Thermal camera FLIR A325sc, (b) the experimental device.

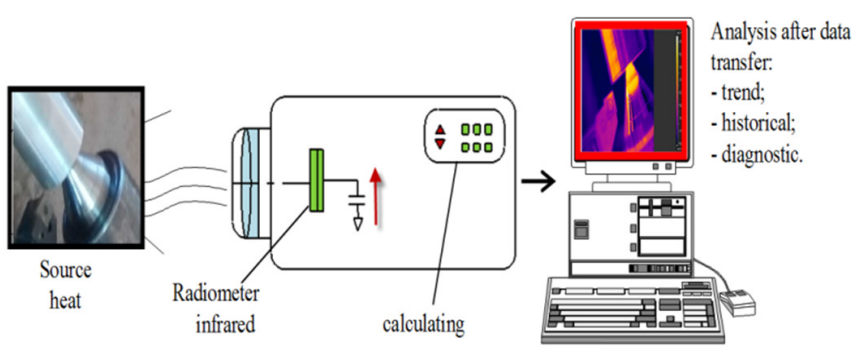

Fig. 7. Chain of acquisition and processing of the thermal data.

- Calibration of the camera: The camera is calibrated in the factory to make accurate measurements and thermal images. However, knowledge of the calibration curve (Figure 8) is essential for advanced control of radiometric measurement. 


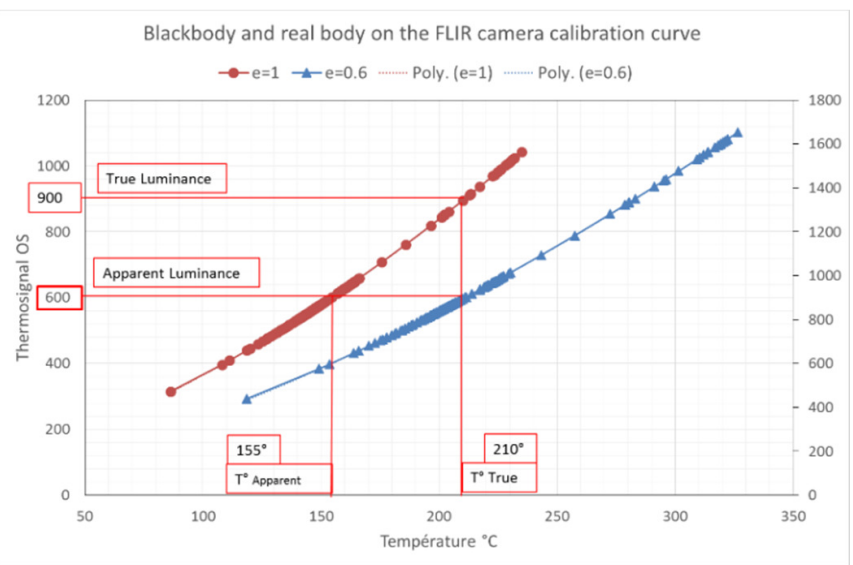

Fig. 8. Calibration curves for the FLIR A325sc.

- Influence of emissivity: When making an infrared measurement, we record the energy $\phi$ emitted by the studied body and refer to Stefan's law of radiation of the black body:

$$
\phi=\sigma \mathrm{T}^{4}
$$

where $\sigma$ is the Boltzmann constant and $\mathrm{T}$ the temperature of the studied body, identified with an ideal black body [9-10].

In addition, the measurement requires knowledge of the emissivity coefficient of the studied body. For this, we put the tool (insert) in an oven whose temperature is known thanks to a standard thermometer. After reaching thermal equilibrium, in situ measurements were taken with the camera. Knowing the temperature in the oven, the temperature measured during machining, and the emissivity coefficient displayed on the camera, the actual coefficient of emissivity of the tool is deduced during machining using (6) [9]. We have taken the same approach to determine the emissivity of the machined material.

\section{B. Preliminary Tests}

In order to verify the possibility of recording the influence and the variability of the thermal fluctuations during the machining, a first series of tests was conducted to control the sensitivity and the capacity of our measuring system to capture and analyze the thermograms (Figure 9). These preliminary tests were carried out under the variability conditions summarized in Table IV, in which the results of the experiment for the qualification and validation of the measurement method are grouped. Over the length of the machining, we chose 10 positions for the temperature reading, using the camera software. These points are taken during the machining stabilization period. The experimental results illustrated in Figure 10 allow us to conclude that the temperature variations are very small in the steady state for invariant cutting parameters. On the other hand, the heat flux generated during machining is largely evacuated by the chip.

In Figure 11, the curves represent the temperatures of the chip, the machined surface and the cutting edge of the tool. Two curves (tool-part) have practically the same shape and very close temperature thresholds (near $100^{\circ} \mathrm{C}$ ). On the other hand, the chip temperature curve shows a marked increase in temperature (around $300^{\circ} \mathrm{C}$ ), which confirms the theoretical results which state that the chip evacuates the most important temperature flow.
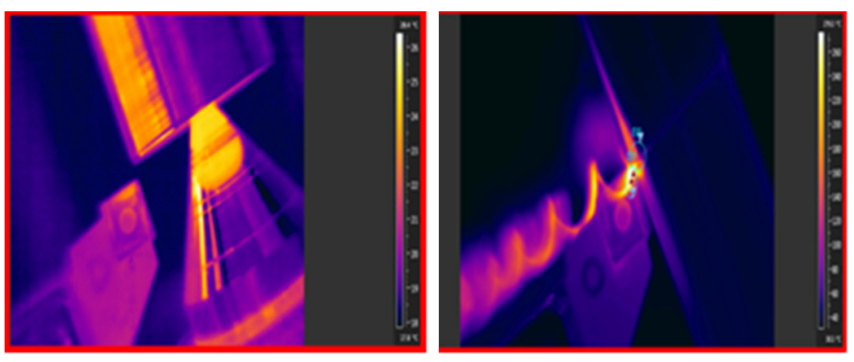

Fig. 9. Thermograms: tool-part.

TABLE IV. EXPERIMENTAL RESULTS

\begin{tabular}{|c|c|c|c|}
\hline Position & Part & Tool & Chip \\
\hline 1 & 114.6 & 79.2 & 300.7 \\
\hline 2 & 117.6 & 89.02 & 298.7 \\
\hline 3 & 117.5 & 93.3 & 299.5 \\
\hline 4 & 114.9 & 95.5 & 302 \\
\hline 5 & 117.6 & 96.2 & 295.5 \\
\hline 6 & 122 & 96.3 & 288.3 \\
\hline 7 & 118 & 97 & 299.3 \\
\hline 8 & 120.1 & 97.3 & 288 \\
\hline 9 & 113.3 & 99.9 & 291.3 \\
\hline 10 & 113.4 & 98.6 & 289.2 \\
\hline Average & 116.90 & 94.23 & 295.25 \\
\hline
\end{tabular}

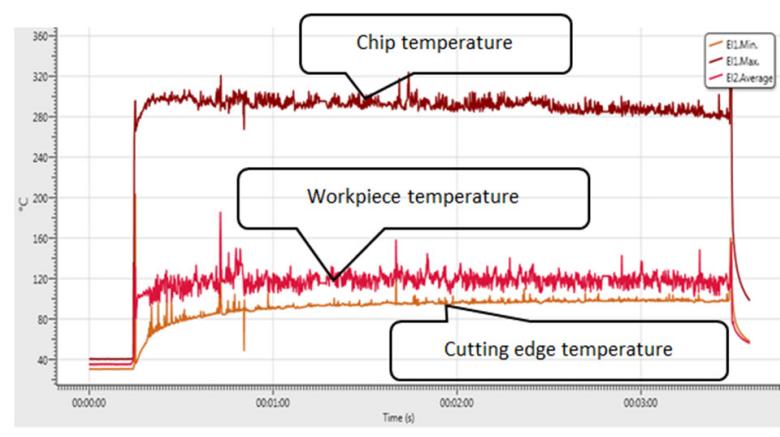

Fig. 10. Temperature variations (quickplot).

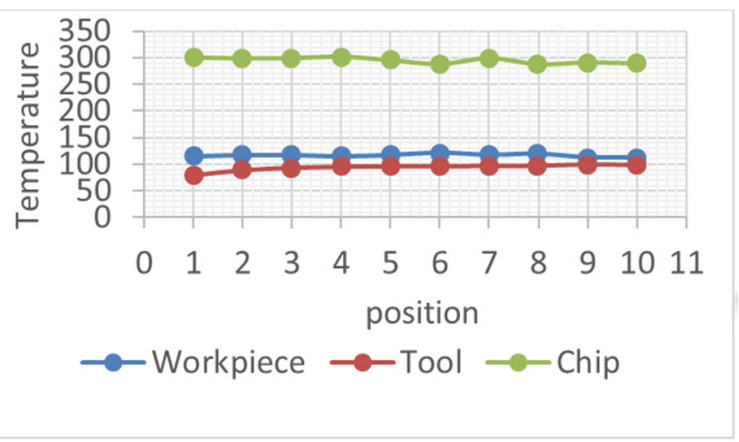

Fig. 11. Temperature variations. 


\section{REFERENCE TESTS}

The large number of variables controlling the manufacturing process requires mathematical models to represent this process. These models should be developed using only the most significant parameters. Tests are used to build first and second order models by multiple regression methods. The aim of developing mathematical models is to understand the combined effect of the parameters involved and to facilitate the optimization of the machining process. During the carried out tests, various machining parameters such as cutting speed, feed rate, and depth of cut, vary according to the design of experiments as independent variables in order to be linked to the response, namely the cutting temperature $[\mathrm{T}=\mathrm{f}(\mathrm{v}, \mathrm{f}, \mathrm{p})]$, by prediction equations of the type:

$$
\mathrm{T}=\mathrm{b}_{0}+\mathrm{b}_{1} \mathrm{x}_{1}+\mathrm{b}_{2} \mathrm{x}_{2}+\mathrm{b}_{3} \mathrm{x}_{3}
$$

The choice of cutting conditions was conditioned by the range of rotational speeds of the machine and the temperature measurement range of the infrared camera. Table $\mathrm{V}$ summarizes the results of the experiments. Figure 12 shows the effect of cutting conditions on temperature variation. Changing the depth of cut has a very high effect on the cutting temperature while the cutting speed and feed rate have a moderate effect on the cutting temperature.

TABLE V. CUTTING PARAMETERS

\begin{tabular}{|c|c|c|c|c|c|}
\hline \multirow{2}{*}{ Parameter } & \multirow{2}{*}{ Code } & \multicolumn{4}{|c|}{ Levels } \\
\cline { 3 - 6 } & & $\mathbf{1}$ & $\mathbf{2}$ & $\mathbf{3}$ & $\mathbf{4}$ \\
\hline Cutting speed Vc $(\mathrm{m} / \mathrm{min})$ & $\mathrm{X}_{1}$ & 78 & 112 & 157 & 220 \\
\hline Feed rate a $(\mathrm{mm} / \mathrm{rev})$ & $\mathrm{X}_{2}$ & 0.08 & 0.11 & 0.14 & 0.20 \\
\hline Depth of cut $\mathrm{P}(\mathrm{mm})$ & $\mathrm{X}_{3}$ & 0.25 & 0.5 & 0.75 & 1 \\
\hline Turning conditions & \multicolumn{6}{|c|}{ Machining without lubrication } \\
\hline
\end{tabular}

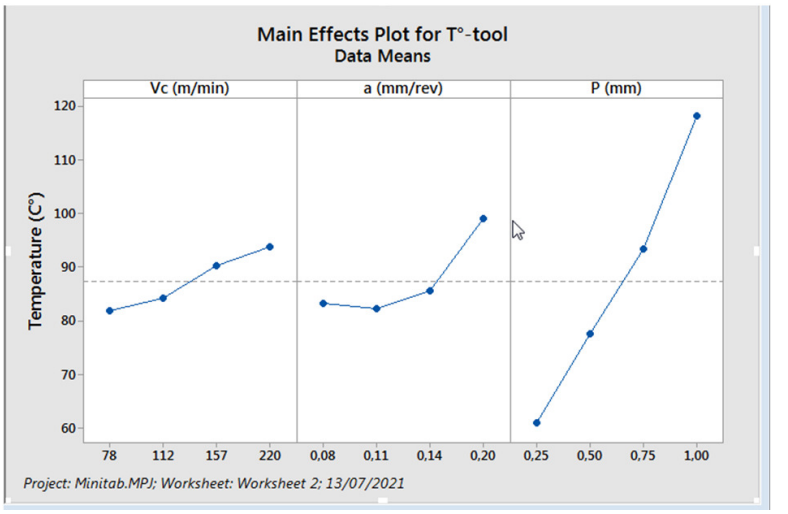

Fig. 12. The effects of cutting conditions on temperature.

After treatment and elimination upstream of the insignificant terms of the model, we obtain the following prediction equation that relates the input and output parameters:

$$
\mathrm{T} \text { tool }=9.7+0.0877 \mathrm{Vc}+139.7 \mathrm{a}+74.96 \mathrm{P}
$$

\section{A. Effects of Cutting Speed on Temperature}

We can see the different levels of the temperature curves according to the cutting speed in Figure 13. They increase with the evolution of the depth of cut. At $112 \mathrm{~m} / \mathrm{min}$ cutting speed (point A) a temperature peak can be observed which can be explained by unfavorable cutting conditions, generating entanglement of the chip around the cutting edge, as shown by the thermogram of Figure 14. At high cutting speed (point B), the chip flow is restored, the cutting temperature drops shown by the thermogram (Figure 15).

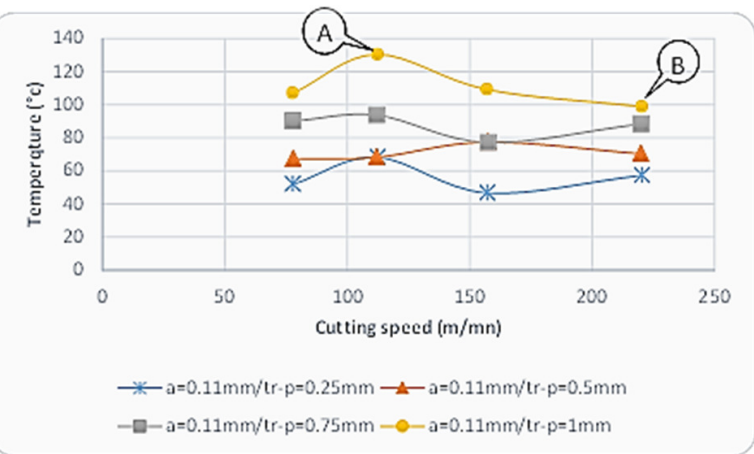

Fig. 13. Temperature according to cutting speed.

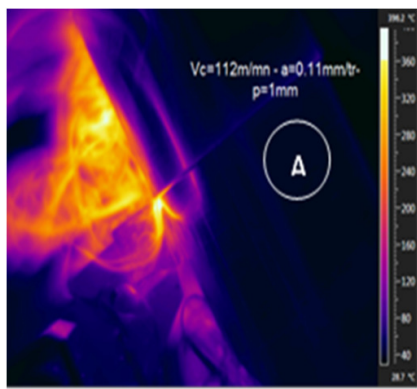

Fig. 14. Thermogram at point $\mathrm{A}$.

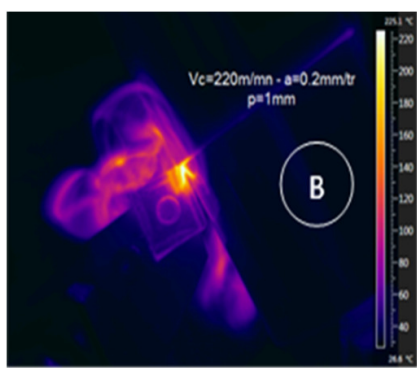

Fig. 15. Thermogram at point $\mathrm{B}$.

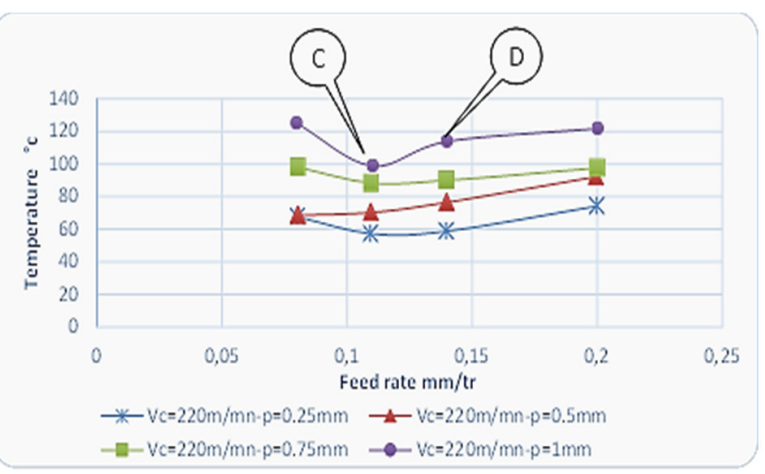

Fig. 16. Temperature according to the feed rate. 


\section{B. Effects of Feed Rate on Temperature}

Figure 16 shows the different levels of the temperature curves depending on the feed rate. They increase with increasing depth of cut. At the feed rate of $0.11 \mathrm{tr} / \mathrm{min}$ (Point $\mathrm{C}$ ) a lower temperature can be observed which can be explained by cutting conditions which favor the flow of the chip around the cutting edge, as shown in the thermogram in Figure 18. At high cutting speed (Point D), the chip remains at the cutting edge, which generates an increase in temperature shown by the thermograms in Figures 17 and 18.

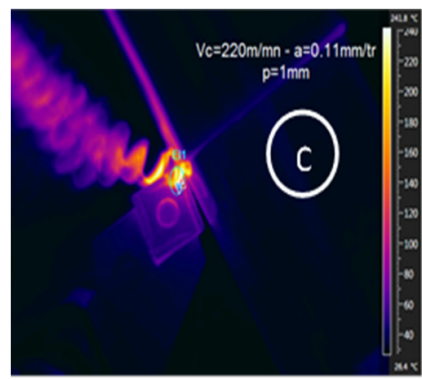

Fig. 17. Thermogram at point $\mathrm{C}$.

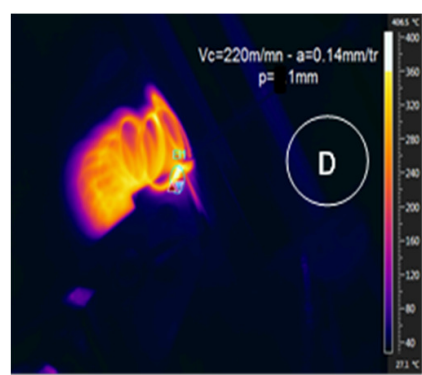

Fig. 18. Thermogram at point D.

\section{Effects of Depth of Cut on Temperature}

The different levels of the temperature curves according to the depth of cut are exhibited in Figure 19. They increase with the evolution of the cutting speed.

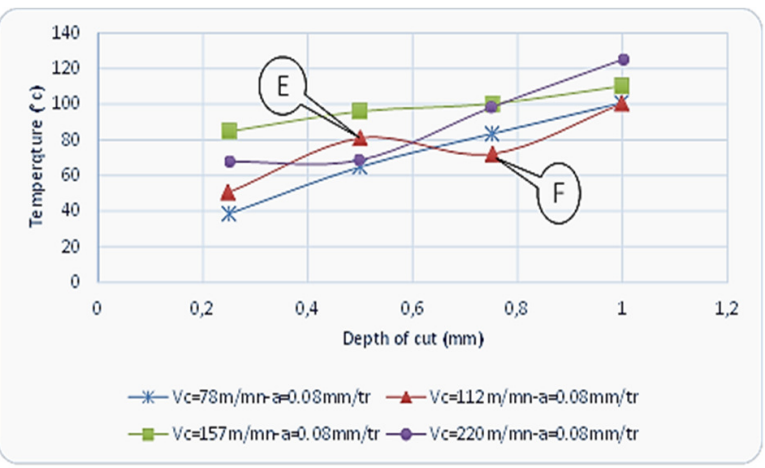

Fig. 19. Temperature as a function of depth of cut.

At the $0.5 \mathrm{~mm}$ depth of cut (point E) a temperature peak can be observed which can be explained by cutting conditions favoring the flow of the chip around the cutting edge, as shown by the thermogram of Figure 20. With a depth of $0.75 \mathrm{~mm}$ (point F), the chip is evacuated more easily, which generates a decrease in temperature (thermogram Figure 21).

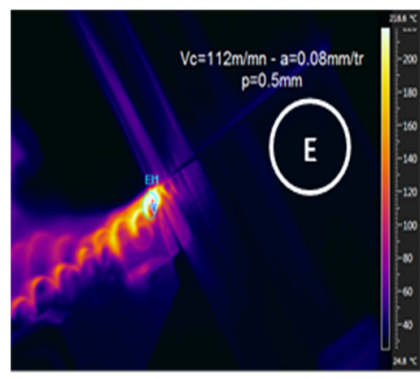

Fig. 20. Thermogram at point E.

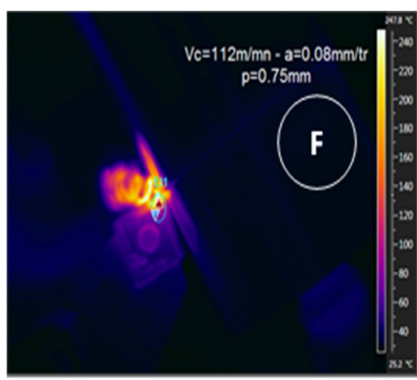

Fig. 21. Thermogram at point $\mathrm{F}$.

\section{CONCLUSIONS}

Knowledge of the distribution of the temperature flow between the cutting tool, the chip and the workpiece provides useful information for optimizing manufacturing conditions. Therefore, it is essential to determine the relationship between the cutting parameters and the temperature distribution. The current paper focuses on the infrared thermography procedure for establishing an experimental methodology, which allows the evaluation of the cutting temperature during the machining operations for different cutting parameters. The experimentation allowed us to evaluate the distribution of the temperature flow on the machined surface of the part, the chip, and the cutting edge. For a large cutting penetration, the friction increases for both the tool and the chip and generates an increase in temperature, so we took (from thermograms) the maximum temperatures of the tool and the chip which were $112.63^{\circ} \mathrm{C}$ and $275.1^{\circ} \mathrm{C}$. The optimal conditions for the good quality of the part are moderate temperatures for high cutting speeds and small depths of cut. The chosen infrared camera used in the experiments has many advantages such as the ability to take measurements without contact with a very little disturbance between the surface of the studied object and its surrounding environment, its measurement capacity in real time, a wide range of operating temperatures, and the ability to adapt to all types of materials. The obtained results during our tests allowed concluding on one hand that the temperature variations are very weak in permanent regimes for invariant cutting parameters and on the other that the heat flux generated during machining is largely evacuated by the chip. The major difficulty in taking the machining sequence by the camera is the winding of the chip, hence the need to choose good cutting 
conditions and to have good protection and fixation of the camera.

In the future, our work will be extended to other materials. We will also try to define a correlation between the cutting temperature and the wear of the tool during machining. We are encouraged by the results of this work to extend to higher speeds (UGV) and to use a more efficient infrared camera for larger measurement range.

\section{REFERENCES}

[1] R. F. Brito, S. R. Carvalho, and S. M. M. Lima E Silva, "Experimental investigation of thermal aspects in a cutting tool using comsol and inverse problem," Applied Thermal Engineering, vol. 86, pp. 60-68, Jul. 2015, https://doi.org/10.1016/j.applthermaleng.2015.03.083.

[2] O. Pantalé, R. Rakotomalala, and M. Touratier, "An ALE threedimensional model of orthogonal, oblique metal cutting processes," International Journal of Forming Processes, vol. vol.1, pp. 371-388, Sep. 1998.

[3] P. K. Wright and E. M. Trent, "Metallographic methods of determining temperatures gradients in cutting tools," 1973

[4] W. Bouzid, "Etude experimentale et numerique de la coupe orthogonale," Ph.D. dissertation, Arts et Métiers ParisTech, Paris, France, 1993.

[5] D. A. Stephenson, "Tool-Work Thermocouple Temperature Measurements-Theory and Implementation Issues," Journal of Engineering for Industry, vol. 115, no. 4, pp. 432-437, Nov. 1993, https://doi.org/10.1115/1.2901786.

[6] I. Bonnet and J. Gabelli, "Probing Planck's law at home," European Journal of Physics, vol. 31, no. 6, pp. 1463-1471, 2010, https://doi.org/ 10.1088/0143-0807/31/6/012.

[7] N. M. Ravindra, S. Rajyalaxmi Marthi, and A. Bañobre, "Introduction to radiative properties," in Radiative Properties of Semiconductors, Morgan \& Claypool Publishers, 2017, http://doi.org/10.1088/978-1$6817-4112-3 \mathrm{ch} 1$

[8] FLIR, "FLIR SC325 Datasheet." FLIR, 2010.

[9] D. Kara Ali, N. Benhadji Serradj, and M. E. A. Ghernaout, "Qualification and Validation of an in-situ Measurement Method of the Machining Temperature," in Mechanism, Machine, Robotics and Mechatronics Sciences, vol. 58, R. Rizk and M. Awad, Eds. Cham, Switzerland: Springer, 2019, pp. 15-27, https://doi.org/10.1007/978-3319-89911-4_2.

[10] J.-L. Battaglia, A. Kusiak, and C. Pradere, Introduction aux transferts thermiques: cours et exercices corrigés. Paris, France: Dunod, 2020.

[11] M. H. El-Axir, M. M. Elkhabeery, and M. M. Okasha, "Modeling and Parameter Optimization for Surface Roughness and Residual Stress in Dry Turning Process," Engineering, Technology \& Applied Science Research, vol. 7, no. 5, pp. 2047-2055, Oct. 2017, https://doi.org/ 10.48084 /etasr. 1560

[12] N. M. M. Reddy and P. K. Chaganti, "Investigating Optimum SiO2 Nanolubrication During Turning of AISI 420 SS," Engineering, Technology \& Applied Science Research, vol. 9, no. 1, pp. 3822-3825, Feb. 2019, https://doi.org/10.48084/etasr.2537.

[13] M. PradeepKumar, K. Amarnath, and M. SunilKumar, "A Review on Heat Generation in Metal Cutting," International Journal of Engineering and Management Research, vol. 5, no. 4, pp. 193-197, Aug. 2015.

[14] G. Sidebotham, "Heat Transfer Modes: Conduction, Convection, and Radiation," in Heat Transfer Modeling: An Inductive Approach, G. Sidebotham, Ed. Cham, Switzerland: Springer International Publishing, 2015, pp. 61-93, https://doi.org/10.1007/978-3-319-14514-3_3.

[15] D. Pajani and L. Audaire, "Thermographie - Technologies et applications: Thermographie et utilisation des caméras thermiques," Techniques de l'Ingénieur, Mar. 2013, Accessed: Oct. 06, 2021. [Online]. Available: https://www.techniques-ingenieur.fr/basedocumentaire/genie-industriel-th6/mise-en-uvre-de-la-maintenance42136210/thermographie-r2741/thermographie-et-utilisation-descameras-thermiques-r2741v2niv10002.html.
[16] O. Riou, P.-O. Logerais, and J.-F. Durastanti, "Quantitative study of the temperature dependence of normal LWIR apparent emissivity," Infrared Physics \& Technology, vol. 60, pp. 244-250, Sep. 2013, https://doi.org/ 10.1016/j.infrared.2013.05.012.

[17] J. Goupy and L. Creighton, Introduction aux plans d'expériences, 3rd ed. Paris, France: Dunod, 2006.

[18] S. Atlati, "Développement d'une nouvelle approche hybride pour la modélisation des échanges thermiques à l'interface outil-copeau: application à l'usinage de l'alliage d'aluminium aéronautique AA2024T351," Ph.D. dissertation, Université de Lorraine, Lorraine, France, 2012 . 